\title{
Peningkatan Kompetensi Pedagogik Guru SMK Melalui Pelatihan Pembuatan E-Learning
}

\author{
Towip, Yuyun Estriyanto, Ngatou Rohman, Suharno \\ Universitas Sebelas Maret Surakarta \\ email: towip@staff.uns.ac.id
}

\begin{abstract}
The covid-19 pandemic has changed the culture of teaching and learning activities in the schools. Learning activities are conducted online with the use of e-learning. Generally, Vocational High Schools (SMK) already have supporting facilities for the implementation of e-learning such as computer laboratories and adequate internet networks. However, most of the teachers in the schools are still not ready for the massive use of e-learning. For this reason, schools need training for teachers to optimize the use and integration of information and communication technology (ICT) in learning activities. The purpose of this community service is to provide training to teachers of SMK Muhammadiyah Delanggu to make e-learning and implement it in the learning process. This activity involved all teachers of SMK Muhammadiyah Delanggu. The stages of this training are: a) introduction to the concept of online learning (elearning), b) workshop of creating e-learning, and c) application of e-learning into the subjects taught by each teacher. The results of this training: a) the teachers have been able to make learning packages, materials and activities in the e-learning, b) Pedagogical competences of teachers have increased showed by a readiness to integrate ICT in the learning process, and c) The readiness of the school to optimize the application of e-learning to improve the learning process.
\end{abstract}

Keywords: Pedagogic Competence, Training, E-learning 


\begin{abstract}
Abstrak
Pandemi covid-19 telah merubah kultur dalam proses kegiatan belajar-mengajar di Sekolah. Kegiatan-kegiatan pembelajaran mayoritas dilaksanakan dengan metode dalam jaringan (daring) dengan pemanfaatan e-learning. Secara umum, sebagian besar sekolah menengah kejuruan (SMK) telah memiliki fasilitas pendukung untuk pelaksanaan e-learning seperti laboratorium komputer dan jaringan internet yang memadai. Namun, sebagian besar sumber daya manusia (SDM) di sekolah masih belum siap terhadap masifnya peenggunaan e-learning. Untuk itu, sekolah membutuhkan pelatihan bagi guru-guru untuk mengoptimalkan penggunaan dan pengintegrasian teknologi informasi dan komunikasi (TIK) dalam kegiatan pembelajaran. Tujuan pelatihan ini adalah memberikan pelatihan kepada guru-guru SMK Muhammadiyah Delanggu untuk membuat e-learning dan mengimplemetasikannya dalam proses pembelajaran. Kegiatan ini melibatkan seluruh guru SMK Muhammadiyah Delanggu. Tahapan kegiatan pelatihan ini meliputi: a) pengenalan konsep pembelajaran daring (e-learning), b) workshop mengelola elearning, dan c) penerapan e-learning ke dalam mata pelajaran yang diajarkan oleh masing-masing guru. Hasil pelatihan ini: a) guru telah mampu merancang perangkat pembelajaran, materi dan aktifitas belajar di e-learning, b) Semakin meningkatnya kompetensi pedagogik guru ditandai dengan kesiapan guru dalam mengintegrasikan TIK dalam proses pembelajaram, dan c) kesiapan sekolah untuk lebih mengoptimalkan penerapan e-learning untuk meningkatkan proses pembelajaran.
\end{abstract}

Kata Kunci: Kompetensi Pedagogik, Pelatihan, e-learning

\title{
PENDAHULUAN
}

Perkembangan revolusi industri 4.0 telah mendorong semua aspek menuju era digitalisasi. Hal ini berdampak pula kepada dunia pendidikan saat ini yang dituntut bisa memanfaatkan teknologi digital untuk mencapai tujuan pendidikan nasional. Berbagai peluang dan tantangan muncul sebagai akibat dari perkembangan internet, termasuk kesiapan guru untuk memanfaatkannya. Salah satu upaya pemanfaatan teknologi dalam pendidikan adalah dengan pemanfaatan pembelajaran secara dalam jaringan (daring) melalui fasilitas e-learning. Pembelajaran tidak terbatas hanya mengandalkan pertemuan tatap muka di sekolah, sehingga kesempatan untuk lebih mengekplorasi suatu topik dan keilmuan tertentu akan semakin terbuka. Metode yang digunakan bisa dengan daring secara penuh (full online) maupun gabungan antara metode tatap muka / luar jaringan dengan dalam jaringan (daring) yaitu dengan blended learning.

E-learning merupakan pembelajaran berbasis web yang bisa diakses dari internet (Horton \& Horton, 2003). Beberapa istilah digunakan dalam penyebutan elearning seperti: virtual learning, online learning maupun web-based learning. Terdapat 3 (tiga) poin syarat sebagai syarat minimal pembelajaran elektronik (e-learning): (1) Pembelajaran melalui pemanfaatan internet (b) adanya media untuk pembelajaran (c) adanya tutor sebagai fasilitator untuk membantu proses pembelajaran melalui elearning (Hartanto, 2016).

Salah satu komponen utama pembelajaran dalam jaringan (daring) adalah guru. Guru berperan sebagai fasilitator dan pembuat media pembelajaran. Guru dituntut untuk terampil menggunakan media pembelajaran sebagai bagian dari kompetensi seorang guru. Sesuai Undang-undang No. 14 tahun 2015 tentang Guru dan Dosen terutama Pasal 8 Guru wajib memiliki kualifikasi akademik, kompetensi, sertifikat pendidik, sehat jasmani dan rohani, serta memiliki kemampuan untuk mewujudkan tujuan pendidikan nasional. Kompetensi guru sebagaimana dimaksud dalam Pasal 8 meliputi kompetensi pedagogik, kompetensi kepribadian, kompetensi sosial, dan kompetensi professional yang diperoleh melalui pendidikan profesi. Kompetensi pedagogik adalah kemampuan mengelola pembelajaran peserta didik. 
Sebagai bagian dari kompetensi pedagogik dalam kaitannya dengan penggunaan e-learning, setidaknya ada 3 (tiga) kompetensi dasar yang harus dimiliki pendidik untuk menyelenggarakan model pembelajaran e-learning, yaitu: 1. Kemampuan untuk membuat desain instruksional (instructional design) sesuai dengan kaidah-kaidah paedagogis yang dituangkan dalam rencana pembelajaran, 2. Penguasaan materi pembelajaran sesuai dengan bidang keahlian dan mata pelajaran yang diberikan. 3. Penguasaan teknologi dalam pembelajaran yakni pemanfaatan internet sebagai sumber pembelajaran ((Hartanto, 2016). Laju perkembangan internet sangat cepat seiring dengan stimulus kebutuhan penggunaan media e-learning yang merupakan integrasi Pendidikan dan teknologi yang dianggap sebagai salah satu media yang cukup berdampak untuk membantu proses belajar (Al-Fraihat, Joy, \& Sinclair, 2017)

Guru di Sekolah menengah kejuruan (SMK) dituntut untuk memiliki kompetensi teknis yang memadai dalam hal penggunaan teknologi. Salah satu tugas guru di SMK adalah membuat aktifitas pembelajaran yang efektif dan efisien agar lulusan SMK mampu diserap oleh dunia usaha dan dunia industri (DUDI) serta mampu berdikari dengan berwirausaha mandiri. Guru SMK harus bisa mengikuti perkembangan teknologi dan tuntutan dunia industri agar bisa mencetak lulusan yang sesuai dengan kebutuhan industri dan mampu berwirausaha. Guru dituntut untuk mampu memaksimalkan semua media yang bisa membantu proses pembelajaran, termasuk penggunaan media e-learning.

Kegiatan pengabdian ini bertujuan untuk meningkatkan kompetensi pedagogik guru SMK dalam hal penggunaan metode pembelajaran daring melalui media $e-$ learning. Hal ini dikarenakan berdasarkan analisis awal, kompetensi pedagogik guru dalam hal merancang metode dan media pembelajaran dalam jaringan (daring) pada guru-guru SMK terutama SMK swasta masih minim. Untuk itulah, kegiatan pengabdian pada masyarakat ini penting dilakukan sebagai upaya membantu peningkatan kompetensi pedagogik guru SMK melalui pelatihan pembuatan e-learning.

Sekolah Menengah Kejuruan (SMK) Muhammadiyah Delanggu merupakan SMK Swasta di bawah naungan Muhammadiyah. SMK Muhammadiyah Delanggu berdiri pada tahun 1993 di Desa Dongkolan, Kecamatan Delanggu, Kabupaten Klaten. Visi SMK Muhammadiyah Delanggu yaitu: berprestasi, professional dan berakhlak mulia. Adapun misinya adalah: menyiapkan peserta didik agar memiliki karir dan mampu berkompetensi, menyiapkan tamatan menjadi pribadi yang kreatif dan inofatif, menyiapkan tenaga kerja yang bertanggung jawab dan berakhlak mulia (Delanggu, 2020)

Sesuai dengan analisis awal mengenai kebutuhan yang dilakukan melalui wawancara pendahuluan dengan kepala sekolah SMK Delanggu, salah satu kebutuhan pengembangan guru saat ini adalah terkait kemampuan guru terhadap perkembangan teknologi terutama teknologi dan metode pengajaran. Apalagi ketika masa pandemi covid-19 yang secara tiba-tiba mengharuskan kebijakan belajar di rumah, sementara itu kegiatan pembelajaran harus tetap dilakukan melalui daring (online). Hal ini cukup menyulitkan para guru, karena sebelumnya mereka belum dipersiapkan untuk bisa mengampu pembelajaran melalui daring (online).

Kondisi ini cukup menyulitkan terutama bagi SMK swasta yang memiliki keterbatasan sumber daya baik itu berupa infrastruktur maupun sumber daya manusia (SDM). Apalagi dengan jumlah guru yang cukup banyak. Berdasarkan studi pendahuluan Kami ke SMK Muhammadiyah Delanggu, dalam situasi wabah covid-19 ini, pembelajaran daring yang dilakukan baru sebatas diskusi melalui grup whatsapp, office 365, sharing melalui google drive dan sekali-kali menggunakan media conference. Untuk itu, diperlukan pengembangan untuk guru dalam bentuk pelatihan pembuatan dan penggunaan media pembelajaran daring (online). 
Tabel 1. Analisis kebutuhan mitra

\begin{tabular}{lllr}
\hline No & $\begin{array}{l}\text { Media / Alat } \\
\text { Belajar }\end{array}$ & n & \multicolumn{1}{c}{ \% } \\
\hline 1 & Microsoft Office 365 & 13 & $34 \%$ \\
2 & Whatsapp (WA) & 7 & $18 \%$ \\
& Kombinasi WA \& & & \\
3 & Ms. 365 & 14 & $37 \%$ \\
4 & Google Classroom & 2 & $5 \%$ \\
5 & Facebook & 1 & $3 \%$ \\
6 & Youtube & 1 & $3 \%$ \\
\hline Jumlah & & 38 & $100 \%$ \\
\hline
\end{tabular}

Berdasarkan analisis permasalahan di atas, maka yang menjadi fokus permasalahan pada pengabdian ini adalah:

a) Kemampuan apa saja yang dikuasai setelah mengikuti pelatihan e-learning di SMK Muhammadiyah Delanggu?

b) Apakah pelatihan dapat meningkatkan kompetensi pedagogik guru SMK Muhammadiyah Delanggu?

\section{PELAKSANAAN DAN METODE}

Terkait permasalahan yang dihadapi oleh SMK Muhammadiyah Delanggu yang telah diungkapkan di atas, Kami akan membantu melalui program pengabdian pada masyarakat dalam bentuk memberikan pelatihan penggunaan e-learning untuk membantu meningkatkan proses dan kualitas pembelajaran di SMK Muhammadiyah Delanggu. Platform e-learning yang akan digunakan adalah google classroom. Google classroom banyak dipilih sebagai media pembelajaran e-learning karena desain dari Google Classroom sudah tidak asing lagi bagi guru karena mereka sudah menggunakan beberapa produk dari Google via akun Google Apps. Peserta sangat menyukai bagaimana konektivitas antara Google Classroom dengan akun Google Drive. Kegunaan dari drive membuat tugas-tugas lebih mudah disimpan dan terorganisir (Izenstark \& Leahy, 2015).

Pengabdian ini dilakukan di SMK Muhammadiyah Delanggu, Klaten. Di SMK Muhammadiyah Delanggu terdapat 6 jurusan yaitu: 1. Teknik kendaraan ringan otomotif, 2. Akuntansi Keuangan Lembaga, 3. Otomatisasi tata kelola perkantoran, 4. Bisnis daring dan pemasaran 5. Asisten keperawatan dan 6. Farmasi klinis dan komunitas. Jumlah peserta pelatihan sejumlah 26 orang guru yang terdiri dari guru normatif, adaptif dan guru produktif. Pemilihan peserta pelatihan berdasarkan rekomendasi yang di ajukan oleh kepala sekolah dengan mempertimbangkan latar belakang jurusan, jenis kelamin, pengalaman dan kemampuan. Hal ini berdasarkan asumsi bahwa kepala sekolah mengetahui program pengembangan dan kebutuhan masing-masing guru.

Sebagai bagian kegiatan pengabdian ini, tim pengabdian bertugas sebagai instruktur pelatihan meliputi kegiatan merencanakan, melaksanakan dan mengevaluasi kegiatan pelatihan pembuatan e-learning dengan Google Classroom. Modul pelatihan telah dibuat dan diberikan pada saat pelatihan berlangsung. 


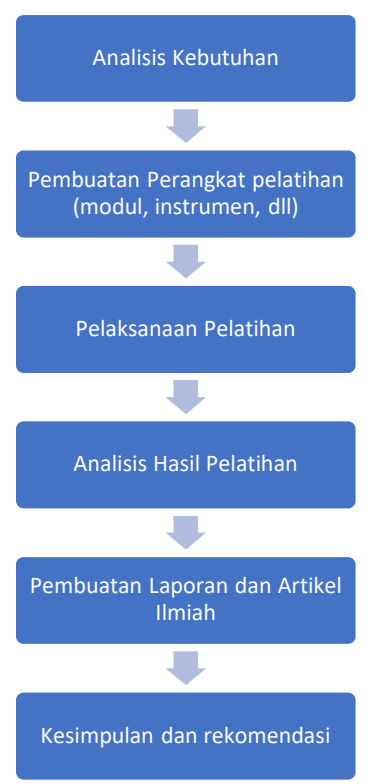

Gambar 1. Diagram Alir Kegiatan Pengabdian

\section{HASIL DAN PEMBAHASAN.}

Kegiatan pelatihan merupakan kegiatan inti dalam program pengabdian kepada masyarakat sebagai salah satu pelaksanaan Tridarma perguruan tinggi. Kegiatan ini telah dilaksanakan pada hari rabu, 16 september 2020 dengan menggunakan metode dalam jaringan (daring). Pelatihan diikuti oleh 26 peserta pelatihan yang terdiri guruguru SMK Muhammadiyah Delanggu.

\begin{tabular}{lllll}
\multicolumn{5}{c}{ Tabel 2. Peserta pelatihan } \\
\hline No & $\begin{array}{l}\text { Kelompok } \\
\text { Guru }\end{array}$ & n & \% & Keterangan \\
\hline & Adaptif & 7 & $27 \%$ & $\begin{array}{l}\text { Matematika. } \\
\text { Kimia, biologi } \\
\text { B. Indo, }\end{array}$ \\
& & & & $\begin{array}{l}\text { Inggris, BK, } \\
\text { Normatif }\end{array}$ \\
& & 11 & $42 \%$ & $\begin{array}{l}\text { PAI } \\
\text { Chassis, }\end{array}$ \\
& & & & $\begin{array}{l}\text { Farmasi, } \\
\text { Kearsipan }\end{array}$ \\
\hline 3 & Produktif & 8 & $31 \%$ & \\
\hline Jumlah & & $\mathbf{2 6}$ & $100 \%$ & \\
\hline
\end{tabular}

Jumlah ini berkurang dari data sebelumnya yang telah terkonfirmasi sebanyak 38 orang calon peserta pelatihan. Beberapa peserta yang sudah konfirmasi keikutsertaan dalam pelatihan, pada saat pelaksanaan tidak hadir dikarenakan ada tugas mengajar dan tugas tambahan lainnya berbarengan dengan kegiatan pelatihan tersebut. Meskipun beberapa peserta tidak hadir, akan tetapi Sebagian besar peserta sudah mewakili keseluruhan guru di SMK Muhammadiyah Delanggu yang terdiri dari guru adaptif, normatif dan produktif.

Secara umum, kegiatan pengabdian ini berjalan lancar, efektif dan efisien. Secara garis besar, berikut deskripsi hasil pelatihan:

1. Sesi pertama dilaksanakan di pagi hari dimulai pukul 08.00 sampai dengan 12.00 . Sesi pertama berisi pemberian materi oleh tim instruktur yang telah didapat di sesi pertama. Pada sesi pertama pelatihan, terlihat antusiasme dari peserta pelatihan dengan ditandai terjadinya diskusi interaktif tentang teknis pembuatan kelas, pengisian materi, penugasan dan penilaian di google classroom. Untuk 
mengetahui sejauhmana peserta mengetahui tentang google classroom, maka di awal sesi pertama dilakukan pooling dengan hasil sebagai berikut:

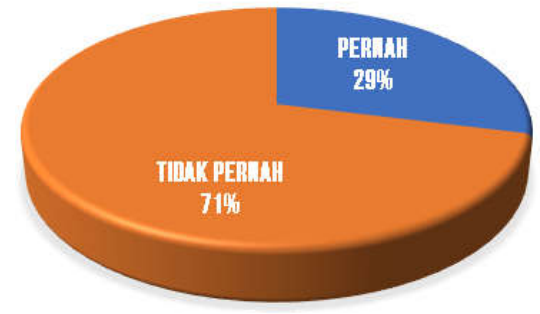

Gambar 2. Pengalaman menggunakan google classroom

Hasilnya menunjukkan bahwa mayoritas peserta $(71 \%)$ belum pernah menggunakan google classroom dalam pembelajaran. Hal ini menjadi catatan bagi instruktur dalam strategi pemberian materi, agar kegiatan pelatihan bisa berjalan efektif dan efisien.

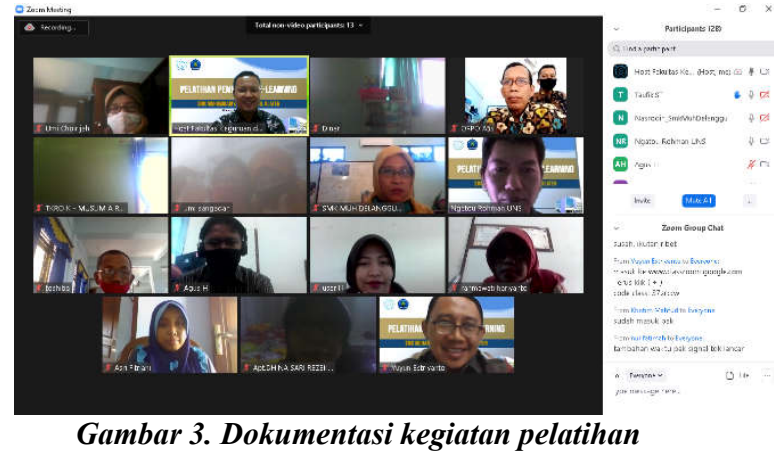

2. Sesi kedua merupakan sesi latihan dan praktek masing-masing peserta untuk mengaplikasikan materi yang telah didapat di sesi pertama. Setiap peserta diwajibkan membuat minimal 1 kelas di google classroom beserta pengaturan aktifitas kegiatan belajar mengajar sampai penilaian sesuai kelas masing-masing.

Berikut contoh interaksi yang terjadi selama kegiatan pelatihan berlansung:

"Assalamu'alaikum... Maaf pak mau tanya, yg dikirim apa saja nggeh pak? Kalau sesuai modul, apakah semua atau hanya file rpp, video,ppt, assigment, quiz".

"Mohon izin bertanya bapak, penugasaanya membuat kelas dan mengikuti modul saja? atau berupa screenshoot semua langkah, sesuai yang ditugaskan Bapak?" "Berikut saya kirimkan link classroom saya Pak, mohon komentarnya apabila ada beberapa revisi, terima kasih."

Salah satu indikator keberhasilan kegiatan pelatihan ini adalah guru mampu untuk merancang pembelajaran daring minimal untuk 1 (satu) kali pertemuan. Guruguru mampu untuk membuat perangkat materi pembelajaran satu pertemuan meliputi: perangkat rencana pelaksaan pembelajaran (RPP), materi ajar beserta aktifitas pembelajaran dan evaluasi pembelajaran dalam bentuk soal atau quiz. Berikut contoh hasil praktek penerapan e-learning berbasis google classroom sesuai dengan peminatan salah satu guru kelas: 


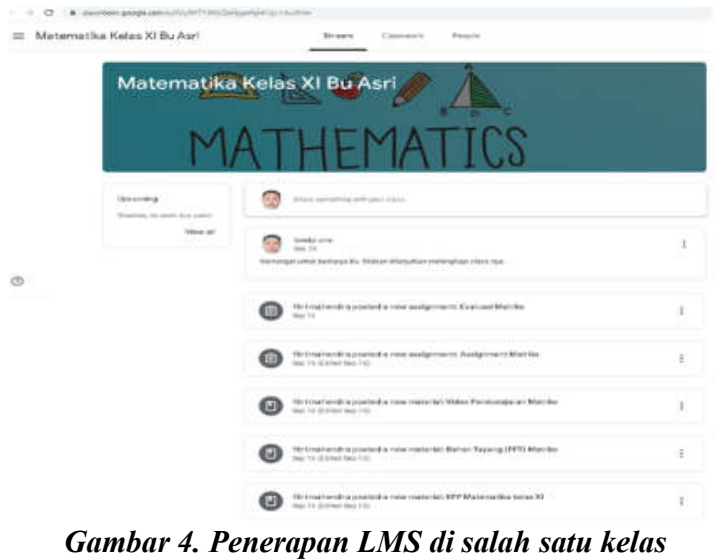

Penggunaan dan pengintegrasian teknologi informasi dan komunikasi (TIK) dalam pembelajaran dapat meningkatkan kesiapan guru (Rahmi \& Hidayati, 2020). Sejalan dengan itu, pelatihan pembuatan e-learning di SMK Muhammadiyah Delanggu, Klaten telah meningkatkan kesiapan dan kepercayaan diri guru dalam melaksanakan pembelajaran dalam jaringan (daring). Hal ini juga telah meningkatkan kompetensi pedagogik guru dalam menyelenggarakan proses pembelajaran yang lebih efektif dan efisien sesuai dengan tuntutan perkembangan abad 21.

Dilihat dari daya dukung sekolah dan kesiapan infrastrukturnya, kegiatan pelatihan ini mendapat dukungan dan apresiasi dari pimpinan dan kepala sekolah SMK Muhammadiyah Delanggu. Hal ini ditandai dengan kesediaan kepala sekolah untuk membuka kegiatan pelatihan dan sekaligus menjadi peserta pelatihan. Selain itu, kesiapan infrastruktur sekolah untuk penggunaan TIK dalam pembelajaran cukup memadai, dengan tersedian laboratorium komputer dan akses internet yang memadai. Bahkan laboratorium komputer menjadi tempat latihan dan praktek para guru ketika pelatihan berlangsung meskipun kegiatan dilaksanakan secara dalam jaringan (daring). Kegiatan pelatihan ini bisa menjadi trigger pihak sekolah untuk lebih mengoptimalkan integrasi TIK khususnya dalam penerapan e-learning untuk meningkatkan kualitas proses proses pembelajaran.

\section{KESIMPULAN}

Kegiatan pelatihan e-learing terhadap guru-guru SMK Muhammadiyah Delanggu telah berjalan dengan lancar. Indikator keberhasilan pelatihan ini adalah: a) guru telah mampu merancang perangkat pembelajaran, materi dan aktifitas belajar di e-learning, b) Semakin meningkatnya kompetensi pedagogik guru ditandai dengan kesiapan guru dalam mengintegrasikan TIK dalam proses pembelajaram, dan c) kesiapan sekolah untuk lebih mengoptimalkan penerapan e-learning untuk meningkatkan proses pembelajaran. Harapannya setelah kegiatan ini, guru dan manajemen sekolah semakin termotivasi untuk terus memperbaiki kualitas pembelajaran sehingga dihasilkan kualitas lulusan SMK yang bermutu.

\section{UCAPAN TERIMA KASIH}

Kami segenap tim pengabdian mengucapkan terima kasih kepada seluruh pihak yang telah membantu terlaksananya kegiatan pengabdian ini. Tim LPPM Universitas Sebelas Maret (UNS), kepala sekolah dan seluruh guru-guru SMK Muhammadiyah Delanggu sebagai mitra pengabdian.

\section{DAFTAR PUSTAKA}

Al-Fraihat, D., Joy, M., \& Sinclair, J. (2017). Identifying success factors for e-learning in higher education. Proceedings of the International Conference on e-Learning, ICEL, (April 2020), 247-255. 
Delanggu, S. muhammadiyah. (2020). Profil.

Hartanto, W. (2016). Penggunaan E-Learning sebagai Media Pembelajaran. Jurnal Pendidikan Ekonomi, 10(1), 1-18.

Horton, W., \& Horton, K. (2003). E-learning Tools and Technologies: A consumer's guide for trainers, teachers, educators, and instructional designers. Publish.

Izenstark, A., \& Leahy, K. L. (2015). Google classroom for librarians: features and opportunities. Library Hi Tech News, 32(9), 1-3. https://doi.org/10.1108/LHTN05-2015-0039

Rahmi, U., \& Hidayati, A. (2020). Pelatihan E-Learning untuk Mengintegrasikan TIK dalam Pembelajaran bagi Guru-guru SMA The Training of E-Learning as ICT Integration in Instructional for Senior High School Teachers. Jurnal Panrita Abdi, 4(1), 34-41. 